\title{
QUALIDADE DE SEMENTES DE SOJA ARMAZENADAS APÓS RECOBRIMENTO COM AMINOÁCIDO, POLÍMERO, FUNGICIDA E INSETICIDA ${ }^{1}$
}

\author{
MARCOS PAULO LUDWIG ${ }^{2}$, ORLANDO ANTONIO LUCCA FILHO ${ }^{3}$, LEOPOLDO BAUDET4, \\ LUIZ MARCELO COSTA DUTRA ${ }^{5}$, SUEMAR ALEXANDRE GONÇALVES AVELAR ${ }^{6}$, RENATO LOPES CRIZEL ${ }^{7}$
}

\begin{abstract}
RESUMO - Objetivou-se com o presente trabalho avaliar o efeito do tratamento e/ou recobrimento de sementes de soja com aminoácido, polímero, fungicida e inseticida sobre os atributos fisiológicos e sanitários das sementes. Foi realizado um experimento utilizando os tratamentos: 1) testemunha; 2) fungicida (Fludioxonil + Metalaxil); 3) aminoácido (PT-4-0 $\left.{ }^{\circledR}\right)$; 4) polímero (Polyseed $\mathrm{CF}^{\circledR}+$ Colorseed $^{\circledR}$ ); 5) fungicida + aminoácido; 6) fungicida + inseticida (Thiametoxam); 7) fungicida + polímero; 8) fungicida + inseticida + polímero e 9) fungicida + aminoácido + inseticida. Após os tratamentos às sementes foram armazenadas e sua qualidade avaliada a cada 60 dias quanto à germinação, vigor e sanidade. A aplicação do aminoácido isolado afeta positivamente a germinação das sementes de soja, porém quando combinado com fungicida e polímero não melhora o desempenho das sementes. A germinação foi afetada negativamente com o uso do fungicida, porém a combinação de fungicida e polímero não apresentou este efeito. A aplicação do fungicida reduziu a incidência dos fungos avaliados, com exceção da Cercospora sp. A utilização de polímero não afeta o controle de fungos pelo fungicida, indicando que a combinação dos mesmos pode ser utilizada.
\end{abstract}

Termos para indexação: Glycine max, tratamento, armazenamento de sementes, vigor.

\section{SEED QUALITY OF STORED SOYBEAN AFTER COATING WITH AMINO ACID, POLYMER, FUNGICIDE AND INSECTICIDE}

\begin{abstract}
The objective of this study was to evaluate the effect of soybean seed coating treatment with amino acid, polymer, fungicide and insecticide on physiological and health quality. The treatments were: 1 ) control; 2) fungicide (Fludioxonil + Metalaxil); 3 ) amino acid (PT-4-0 ${ }^{\circledR}$ ); 4) polymer (Polyseed $\mathrm{CF}^{\circledR}+$ Colorseed $^{\mathbb{}}$ ); 5) fungicide + amino acid; 6) fungicide + insecticide (Thiametoxam); 7) fungicide + polymer; 8) fungicide + insecticide + polymer; and 9) fungicide + amino acid + insecticide. Germination, vigor and seed health were evaluated. The seeds were stored for six months and evaluations done every 60 days. The application of amino acid alone
\end{abstract}

${ }^{1}$ Submetido em 08/04/2010. Aceito para publicação em 07/02/2011. Parte da Dissertação de Mestrado do primeiro autor apresentada a UFPelFAEM, PPG em Ciência e Tecnologia de Sementes.

${ }^{2}$ Eng. Agrônomo, Dr. Professor do IFRS-Campus Ibirubá, Rua Nelsi Ribas Fritsh 1.111, 98200-000, Ibirubá, RS. plmarcos1@yahoo.com.br.

${ }^{3}$ Eng. Agrônomo, Dr., Professor Departamento de Fitotecnia, UFPel, 96001-970, Pelotas, orlando_lucca@hotmail.com.

${ }^{4}$ Eng. Agrônomo, Ph D., Professor Departamento de Fitotecnia, UFPel, 96001-970, Pelotas,1mbaudet@gmail.com.
${ }^{5}$ Eng. Agrônomo, Dr., Professor Departamento de Fitotecnia, CCR, UFSM, 97105-900, Santa Maria, drmarcelodutra@yahoo.com.br.

${ }^{6}$ Eng. Agrônomo, MS., Doutorando do PPG. em C. e T. de Sementes, FAEM-UFPel, 96001-970, Pelotas, suemaralexandre@yahoo.com.br.

${ }^{7}$ Aluno do Curso de Agronomia - UFPel-FAEM, 96001-970, Pelotas. Bolsista BIC/FAPERGS, renato.crizel@hotmail.com. 
positively affected seed germination but when combined with fungicide and polymer there was no improvement in seed performance. Germination was negatively affected by using fungicides but the combination of fungicide and polymer had no effect. Fungicide application reduced fungus incidence, except for Cercospora sp. The use of polymer did not affect fungus control by the fungicide, indicating that this combination can be used.

Index terms: Glycine max, treatment, storage, vigor.

\section{INTRODUÇÃO}

A soja é a cultura com maior área cultivada e produção no Brasil. No ano de 2009 foram cultivados cerca de 22 milhões de hectares o que produziu em torno de 57 milhões de toneladas de grãos, (IBGE, 2010). De forma geral, há um crescimento da percepção da importância do uso de sementes de qualidade pelos produtores. A utilização de sementes com qualidade e o emprego de produtos que possibilitem melhoria do desempenho destas no campo são elementos importantes para uma alta produção agrícola

O uso de aminoácidos no tratamento de sementes, de forma isolada ou em combinação com outros produtos, é ainda uma técnica incipiente que necessita ser mais bem avaliada. Por ser esta uma técnica relativamente nova, justifica-se a observação dos efeitos deste produto sobre a qualidade inicial das sementes de soja. Os possíveis benefícios alcançados com o uso de aminoácidos estão associados com a melhoria da germinação, da produção de plantas com raízes mais fortes, plantas mais vigorosas e firmes, enchimento mais uniforme de grãos e uma produtividade elevada. Vale ressaltar que a aplicação de aminoácidos em culturas não tem o objetivo de suprir a necessidade das plantas para a síntese proteica, mas agir como ativadores do metabolismo fisiológico (Floss e Floss, 2007).

Como possíveis benefícios advindos do recobrimento das sementes com polímeros, podem ser destacados o aumento do tamanho e peso das sementes, alteração do formato, redução da necessidade de aplicação de grafite no momento da semeadura, diminuição das perdas de produtos aplicados na superfície das sementes, melhoria da eficiência e da distribuição dos produtos sobre a semente, proteção do operador contra a contaminação com produtos químicos, redução da variação de temperatura e umidade e agregação de valor comercial as sementes. Porém, estes produtos para serem usados não devem interferir de forma negativa sobre a qualidade fisiológica dos lotes de sementes. Os bons resultados obtidos com a utilização de fungicidas fizeram com que no Brasil mais de 90\% das sementes de soja sejam tratadas com produtos químicos. Também os inseticidas vêm sendo usados de forma mais frequente, alcançando 30\% de aplicação em semente de soja. Esses dados demonstram que os produtores estão adotando as novas tecnologias desenvolvidas pela pesquisa, diminuído os riscos de produção e dando condições para que a cultura se estabeleça e possa desempenhar seu potencial produtivo (Baudet e Peske, 2006).

O tratamento químico de sementes é a forma mais difundida para o controle de patógenos transmitidos por sementes, compreendendo a aplicação de fungicida, inseticida, antibiótico e nematicida. Para que o tratamento químico seja eficiente, deve-se selecionar um produto capaz de erradicar os patógenos presentes nas sementes, não ser tóxico às plantas, ao homem e ao ambiente, apresentar alta estabilidade, aderência e cobertura, não ser corrosivo, ser de baixo custo e fácil aquisição, além de ser compatível com outros produtos (Lucca Filho, 2006). Goulart (2000), além de observar a eficiência no controle de patógenos detectou aumento da emergência a campo e rendimento de grãos com a utilização de fungicidas. Em milho também Luz e Pereira (1998) observaram comportamento similar.

Durante o armazenamento sob condições não controladas, as sementes estão expostas a oscilações de temperatura e umidade relativa, ao ataque de pragas e fungos de armazenamento, o que pode contribuir para a redução da qualidade das mesmas. Assim, o tratamento de sementes com fungicidas e polímeros pode contribuir para a redução destes efeitos nocivos, contribuindo para a manutenção da qualidade das sementes, durante o período que as mesmas permanecem em repouso seminal (Pereira et al., 2005; Karam et al., 2007). 
Objetivou-se com o presente trabalho avaliar o efeito do tratamento e/ou recobrimento de sementes de soja com aminoácido, polímero, fungicida e inseticida sobre os atributos fisiológicos e sanitários das sementes.

\section{MATERIAL E MÉTODOS}

O experimento foi realizado na Unidade de Beneficiamento de Sementes (UBS) da Faculdade de Agronomia Eliseu Maciel (FAEM) da Universidade Federal de Pelotas (UFPel), município de Capão de Leão, RS, e no Laboratório Didático de Análise de Sementes da FAEM/UFPel. A cultivar de soja utilizada foi a CD 219 , classificada na peneira de furos redondos de 5,0mm. O trabalho foi conduzido de outubro de 2007 a março de 2008.

Os produtos utilizados foram o fungicida, Maxin $\mathrm{XL}^{\circledR}$, na dose de $100 \mathrm{~mL} .100 \mathrm{~kg}$ de sementes, que tem como principio ativo Fludioxonil + Metalaxil; o inseticida Cruiser $^{\circledR}$ a base de Thiametoxam, na dose de $100 \mathrm{~mL} .100$ $\mathrm{kg}$ de sementes do produto comercial; o aminoácido PT-4- $0^{\circledR}$ na dose de $150 \mathrm{~mL} .100 \mathrm{~kg}$ de sementes; e os produtos para o recobrimento polímero Polyseed $\mathrm{CF}^{\circledR}+$ Colorseed $^{\circledR}$ na dose de $100 \mathrm{~mL} .100 \mathrm{~kg}$ de sementes de cada produto. Os tratamentos aplicados foram: 1) testemunha; 2) fungicida; 3) aminoácido; 4) polímero; 5) fungicida + aminoácido; 6) fungicida + inseticida; 7) fungicida + polímero; 8 ) fungicida + inseticida + polímero; e 9) fungicida + aminoácido + inseticida. Os tratamentos foram realizados em uma tratadora Grazmec com sistema de aspersão Spray System ${ }^{\circledR}$.

As sementes de soja foram tratadas com um volume de calda de $600 \mathrm{~mL} .100 \mathrm{~kg}$ de sementes, sendo realizados dois testes preliminares com objetivo de adequar as doses do polímero com os produtos utilizados e a regulagem da máquina (Grazmec Spray System ${ }^{\circledR}$ ) utilizada para recobrimento. Após o tratamento, foi retirada uma amostra de sementes que foi levada ao laboratório para realização das análises. As demais sementes permaneceram armazenadas em sacos de papel na UBS sob condições não controladas, durante seis meses.

Avaliaram-se o grau de umidade, a germinação, o vigor (primeira contagem, peso da massa seca das plântulas e germinação à baixa temperatura) e a sanidade das sementes em zero, 60, 120 e 180 dias após o tratamento. Também foram registrados os dados de umidade relativa ambiental e as temperaturas médias e máximas coletados pela Estação Agroclimatológica de Pelotas.
Grau de umidade: o método utilizado foi o da estufa a $105^{\circ} \mathrm{C} \pm 3^{\circ}$ por 24 horas, sendo utilizadas duas repetições para cada unidade experimental (BRASIL, 1992).

Umidade relativa do ar, temperaturas média e máxima: foi obtida através da média da umidade relativa dos dez dias anteriores a cada avaliação. A temperatura média foi obtida através da média mensal, já a máxima foi o maior valor da temperatura do mês (Estação Agroclimatológica de Pelotas).

Germinação: realizado segundo as Regras para Análise de Sementes - RAS (BRASIL, 1992), por meio da semeadura de 200 sementes por unidade experimental, divididas em quatro repetições de 50 sementes, em rolo de papel toalha umedecido com água (três vezes seu peso). Os rolos foram colocados em germinador à temperatura de $25{ }^{\circ} \mathrm{C}$ por oito dias, quando foi realizada a avaliação. Os resultados foram expressos em porcentagem de plântulas normais.

Primeira contagem de germinação: realizado conjuntamente ao teste de germinação, sendo a contagem das plântulas normais executada aos cinco dias após inicio do teste. Os resultados foram expressos em porcentagem de plântulas normais.

Peso da massa seca das plântulas: foram utilizadas dez plântulas retiradas durante a primeira contagem da germinação, perfazendo quatro subamostras de dez plântulas para cada repetição. As plântulas foram separadas dos cotilédones que foram eliminados, e as radículas e os hipocótilos foram colocados dentro de sacos de papel, que posteriormente passaram para a estufa com ventilação forçada à temperatura de $60{ }^{\circ} \mathrm{C}$, durante 48 horas. Posteriormente, foi realizada a pesagem em balança analítica.

Germinação à baixa temperatura: o teste foi conduzido de forma semelhante ao teste de germinação, sendo que as sementes foram expostas às condições subótimas de temperatura em $\mathrm{BOD}$ regulada à temperatura de $15{ }^{\circ} \mathrm{C}$. As sementes permaneceram neste ambiente por oito dias, quando foi avaliada a porcentagem de plântulas normais e vigorosas. As plântulas foram consideradas vigorosas quando apresentavam comprimento superior a $13 \mathrm{~cm}$, conforme indicado por (Dias e Alvarenga 1999).

Sanidade: utilizou-se o método do papel filtro ("blotter test"). Inicialmente os gerboxes foram desinfetados com solução de hipoclorito de sódio (1\%). Em cada gerbox foram dispostas duas folhas de papel de mata borrão esterilizadas e umedecidas com água destilada e esterilizada. Foram distribuídas 
25 sementes por gerbox, num total de oito repetições por unidade experimental. Os gerboxes contendo as sementes foram incubados à temperatura de $20^{\circ} \mathrm{C} \pm 2$ ${ }^{\circ} \mathrm{C}$, sob regime alternado de 12 horas de luz e 12 horas de escuro, por um período de sete dias. Ao final desse período, as sementes foram examinadas individualmente ao microscópio estereoscópico, verificando-se a incidência dos fungos fitopatogênicos Rhizoctonia sp.; Fusarium spp.; Colletotrichum sp.; Phomopsis sp.; Alternaria spp.; Cercospora sp. (Neergaard, 1977).

O delineamento experimental foi o inteiramente casualizado, em esquema fatorial 9 x 4 (9 tratamentos: testemunha, fungicida, aminoácido, polímero, fungicida + aminoácido, fungicida + inseticida, fungicida + polímero, fungicida + inseticida + polímero e fungicida + aminoácido + inseticida e quatro épocas de avaliação 0, 60, 120 e 180 dias após tratamento) com 4 repetições.

Os dados obtidos foram submetidos à análise da variância e teste de hipóteses para verificar a significância do efeito dos tratamentos, das épocas e das interações. O teste de comparação de médias foi o de Scott-Knott, a 5\% de significância para o fator tratamento e regressão para o fator época, para a variável sanidade os dados levantados foram transformados $\bigvee_{y}+0.5$ com auxílio do software estatístico SISVAR versão 4.6, (Ferreira, 2003).

\section{RESULTADO E DISCUSSÃO}

Após os tratamentos, o grau de umidade das sementes aumentou 1\% atingindo em média de 14\% (Figura 1). Porém, após 60 dias de armazenamento foi observada redução do grau de umidade em $2,6 \%$ em relação à primeira avaliação. Já na terceira avaliação o grau de umidade aumentou em torno de $0,9 \%$ e na última avaliação reduziu em $0,7 \%$, mostrando a tendência das sementes armazenadas em condições ambientais em alcançar o equilíbrio higroscópico, com a umidade relativa (Figura 1) do meio que as rodeia (Baudet e Villela, 2006).

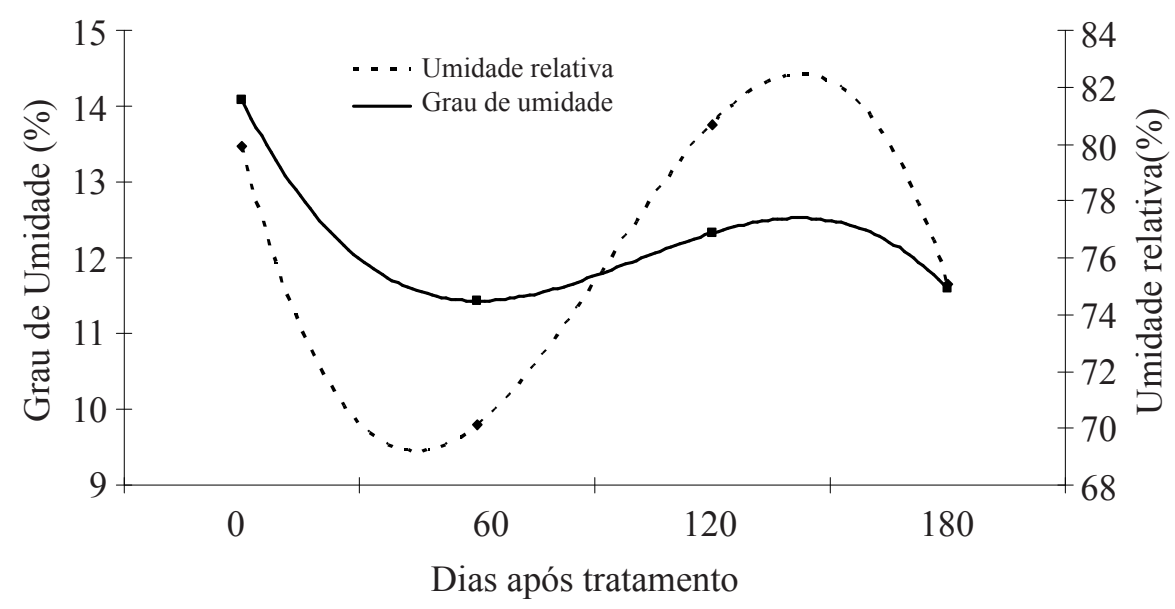

\section{FIGURA 1. Umidade relativa ambiental (\%) e grau de umidade (\%) médio de sementes de soja do cultivar CD 219 após o tratamento e armazenadas em condições ambientais por 180 dias.}

Não houve interação significativa entre os tratamentos e épocas de avaliação para a germinação, porém foi observado efeito significativo entre os dos tratamentos sendo este efeito verificado até o final das avaliações. (Tabela 1). Podem ser observados valores significativamente maiores de germinação no tratamento com aminoácido, pois este tratamento apresentou-se em todas as avaliações no melhor grupo. Estes resultados podem estar relacionados com a ativação de enzimas que favorecem a germinação, fato destacado por (Priyachem 2008).

Pode-se observar ainda na Tabela 1 que a germinação média das sementes de soja estava acima do padrão exigido para a comercialização de sementes. Verificou-se também que as sementes tratadas com fungicida, com fungicida + aminoácido e com fungicida + inseticida não atingiram o padrão mínimo de germinação e ainda apresentaram valores inferiores à testemunha. Após dois meses de armazenamento sob condições ambientais, somente as 
sementes tratadas com aminoácido isolado apresentaram germinação acima do padrão. Fatores que podem explicar a rápida deterioração das sementes são o grau de umidade das sementes de $14 \%$, antes do armazenamento, a umidade relativa e a temperatura elevada durante o período de armazenamento (Figuras 1 e 2).

TABELA 1. Germinação (\%) de sementes de soja do cultivar CD 219, sem tratamento (testemunha) e tratadas e/ou recobertas com polímeros e, armazenadas durante 180 dias.

\begin{tabular}{|c|c|c|c|c|c|}
\hline \multirow{3}{*}{ Tratamentos } & \multicolumn{5}{|c|}{ Germinação (\%) } \\
\hline & \multicolumn{4}{|c|}{ Dias após tratamento } & \multirow{2}{*}{ Média } \\
\hline & 0 & 60 & 120 & 180 & \\
\hline Testemunha & $82 \mathrm{a}$ & $75 \mathrm{a}$ & $72 \mathrm{a}$ & $55 \mathrm{~b}$ & 71 \\
\hline Fungicida & $77 \mathrm{~b}$ & $67 \mathrm{~b}$ & $62 \mathrm{~b}$ & $50 \mathrm{c}$ & 64 \\
\hline Aminoácido & $86 \mathrm{a}$ & $81 \mathrm{a}$ & $79 \mathrm{a}$ & $64 \mathrm{a}$ & 78 \\
\hline Polímero & $83 \mathrm{a}$ & $77 \mathrm{a}$ & $72 \mathrm{a}$ & $50 \mathrm{c}$ & 71 \\
\hline Fungicida + aminoácido & $78 \mathrm{~b}$ & $70 \mathrm{~b}$ & $64 \mathrm{~b}$ & $44 \mathrm{c}$ & 64 \\
\hline Fungicida + inseticida & $79 \mathrm{~b}$ & $69 \mathrm{~b}$ & $71 \mathrm{a}$ & $50 \mathrm{c}$ & 67 \\
\hline Fungicida + polímero & $84 \mathrm{a}$ & $77 \mathrm{a}$ & $75 \mathrm{a}$ & $57 \mathrm{~b}$ & 73 \\
\hline Fungicida + inseticida + polímero & $83 \mathrm{a}$ & $73 \mathrm{~b}$ & $72 \mathrm{a}$ & $50 \mathrm{c}$ & 69 \\
\hline Fungicida + aminoácido + inseticida & $86 \mathrm{a}$ & $79 \mathrm{a}$ & $73 \mathrm{a}$ & $47 \mathrm{c}$ & 71 \\
\hline Média & 82 & 74 & 71 & 52 & 70 \\
\hline C.V. & & & 7,2 & & \\
\hline
\end{tabular}

*Tratamentos seguidos pela mesma letra pertencem ao mesmo grupo pelo teste de Scott-Knott, a 5\% de significância.

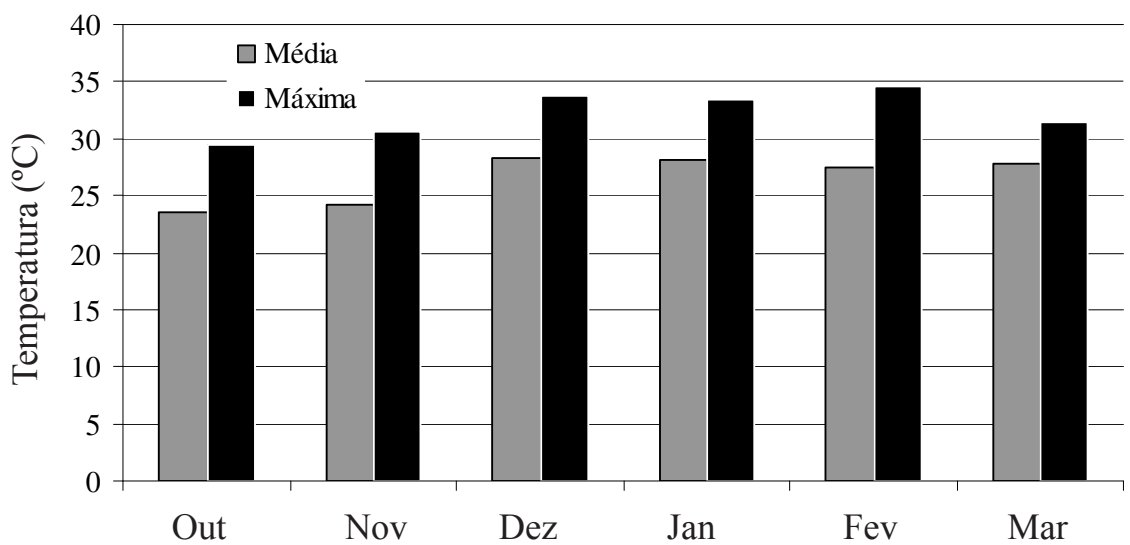

Meses de armazenamento

FIGURA 2. Temperatura média e máxima durante os meses de armazenamento das sementes de soja sob condições não controladas em Capão do Leão, $R S$.

Os piores tratamentos foram aqueles com fungicida isolado, fungicida mais aminoácido e fungicida mais inseticida. A redução da germinação com a aplicação do fungicida e/ou inseticida pode estar relacionada com a ação do ingrediente ativo sobre as sementes, que pode ter acarretado um efeito fitotóxico e redução da germinação das mesmas. Este efeito também se manifestou aos 60 e 120 dias de armazenamento das sementes, resultado semelhante ao obtido por Bays et al. (2007), porém, esses autores ressalvam que estes resultados devem ser 
encarados com a devida cautela, pois a utilização de fungicida é de grande importância para o estabelecimento da cultura da soja. Isto pode ser confirmado pelos dados obtidos na avaliação da sanidade das sementes (Tabela 4) onde o uso de fungicida diminuiu a incidência dos fungos Rhizoctonia sp. (logo após o tratamento); Fusarium spp. (aos 180 dias após o tratamento); Colletotrichum sp. (aos 60 e 180 dias após o tratamento); Phomopsis sp. (aos 60 dias após o tratamento) e Alternaria spp. (aos 60 e 180 dias após o tratamento).

Aos 180 dias após o tratamento as sementes tratadas com aminoácido isolado obtiveram o maior desempenho na germinação, diferindo dos demais tratamentos. O menor desempenho foi obtido no tratamento fungicida + aminoácido, 20\% inferior a germinação do tratamento aminoácido isolado. Com esse resultado infere-se que o uso do aminoácido com fungicida causaria um efeito fitotóxico latente ocasionando redução na germinação (Tabela 1).

Pela análise de regressão (Figura 3A) verifica-se que a função quadrática foi a que melhor se adequou ao comportamento observado, indicando redução da germinação com o decorrer do armazenamento. Possivelmente, este resultado está relacionado com as

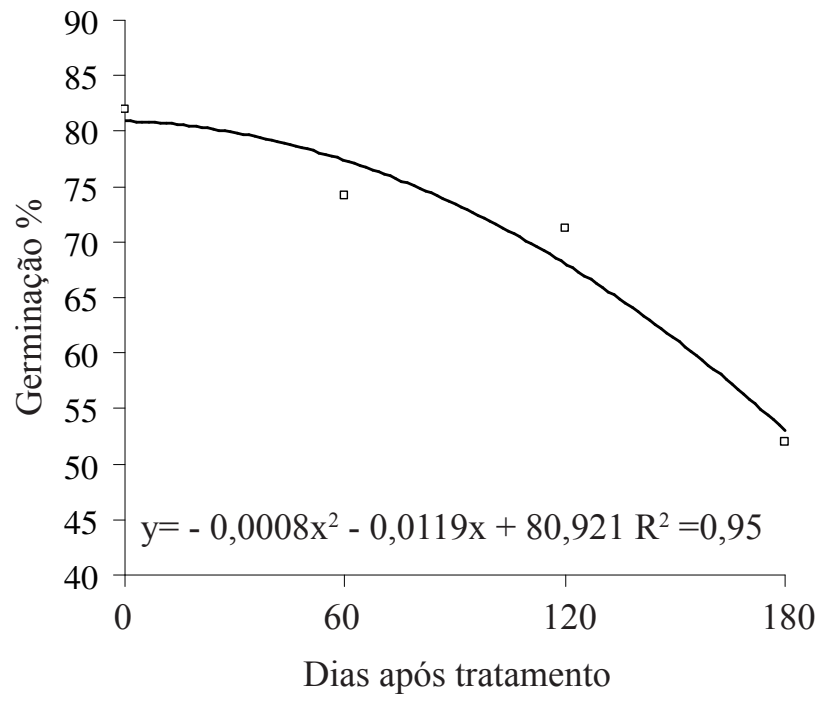

condições de armazenamento, uma vez que as sementes foram armazenadas na UBS sem controle de temperatura e umidade relativa do ar. Essas condições sub-ótimas de temperatura e umidade relativa do ar afetaram a qualidade destas sementes (Figuras 1 e 2). Este resultado é explicado por Kunkur (2007), segundo o qual o declínio da porcentagem de germinação, com o avanço do período de armazenamento, pode ser atribuído ao envelhecimento das sementes, ao consumo de reservas e a redução da capacidade de síntese do embrião.

No período dos 120 até os 180 dias após tratamento, a germinação (Figura 3A) sofreu redução de forma acentuada. Após os 120 dias do armazenamento, a redução da viabilidade das sementes aumentou, possivelmente devido a causas estruturais de suas próprias células, pois as sementes haviam sido armazenadas sob condições adversas por um longo período, expostas à ação da temperatura e umidade do ambiente, o que compromete o funcionamento das organelas celulares, fato explicado por Zimmer (2006) que destaca que sementes de baixo vigor possuem a maioria das células comprometidas e as organelas ineficientes o que ocasiona, tanto redução da germinação, como do vigor das sementes.

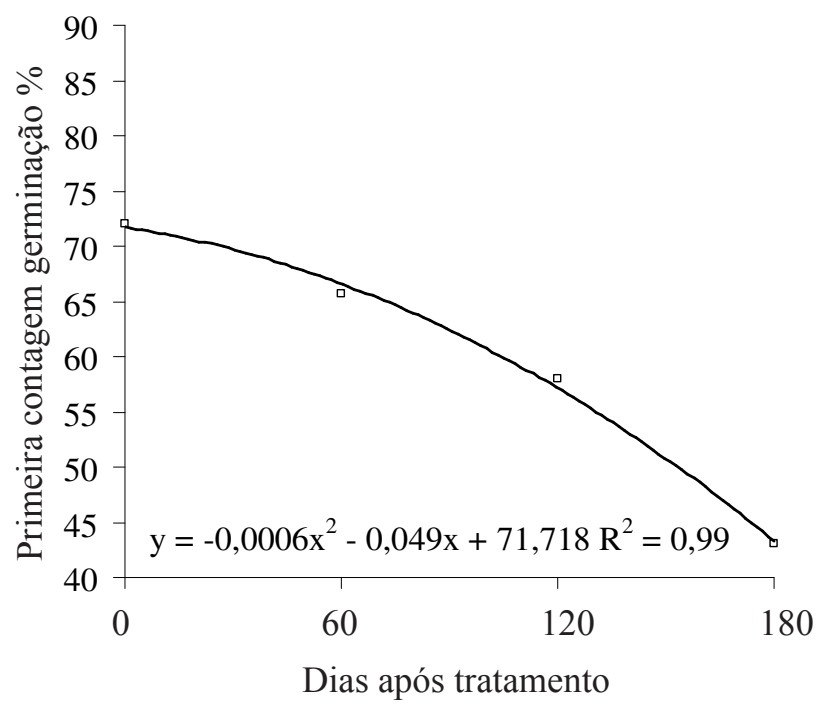

FIGURA 3. Germinação (\%) (A) e primeira contagem da germinação (\%) (B) de sementes de soja do cultivar CD 219, não tratada (testemunha) e tratadas e/ou recobertas e armazenadas em condições não controladas por 180 dias.

Para a primeira contagem de germinação foram detectadas diferenças estatísticas entre os tratamentos e épocas de avaliação. Após o tratamento (Tabela 2), verificou-se maior número de plântulas normais na primeira contagem para a testemunha, aminoácido isolado, fungicida + polímero. Os menores valores 
foram observados nos tratamentos, fungicida e polímero isolado, fungicida + aminoácido, fungicida + inseticida, fungicida + polímero, fungicida + inseticida + polímero e fungicida + aminoácido + inseticida. Estes resultados estão relacionados com a germinação, pois a primeira contagem é obtida conjuntamente ao teste de germinação, porém avaliando as plantas normais aos 5 dias após inicio do teste. Os tratamentos com fungicida e fungicida + aminoácido alcançaram os menores valores de plântulas normais na primeira contagem nas avaliações logo após o tratamento, aos 60 e 120 dias após o tratamento diferindo até da testemunha.

TABELA 2. Primeira contagem da germinação (\%) de sementes de soja do cultivar CD 219, sem tratamento (testemunha) e tratadas e/ou recobertas com polímeros e, armazenadas durante 180 dias.

\begin{tabular}{|c|c|c|c|c|c|}
\hline \multirow{3}{*}{ Tratamentos } & \multicolumn{5}{|c|}{ Primeira contagem da germinação (\%) } \\
\hline & \multicolumn{4}{|c|}{ Dias após tratamento } & \multirow{2}{*}{ Média } \\
\hline & 0 & 60 & 120 & 180 & \\
\hline Testemunha & $76 \mathrm{a}$ & $68 \mathrm{a}$ & $62 \mathrm{~b}$ & $44 \mathrm{~b}$ & 63 \\
\hline Fungicida & $62 \mathrm{~b}$ & $57 \mathrm{~b}$ & $48 \mathrm{c}$ & $41 \mathrm{~b}$ & 52 \\
\hline Aminoácido & $78 \mathrm{a}$ & $73 \mathrm{a}$ & $69 \mathrm{a}$ & $52 \mathrm{a}$ & 68 \\
\hline Polímero & $73 \mathrm{a}$ & $70 \mathrm{a}$ & $60 \mathrm{~b}$ & $42 \mathrm{~b}$ & 61 \\
\hline Fungicida + aminoácido & $65 \mathrm{~b}$ & $60 \mathrm{~b}$ & $47 \mathrm{c}$ & $36 \mathrm{~b}$ & 52 \\
\hline Fungicida + inseticida & $68 \mathrm{~b}$ & $60 \mathrm{~b}$ & $58 \mathrm{~b}$ & $40 \mathrm{~b}$ & 57 \\
\hline Fungicida + polímero & $75 \mathrm{a}$ & $69 a$ & $60 \mathrm{~b}$ & $48 \mathrm{a}$ & 63 \\
\hline Fungicida + inseticida + polímero & $73 \mathrm{a}$ & $65 \mathrm{a}$ & $59 \mathrm{~b}$ & $43 \mathrm{~b}$ & 60 \\
\hline Fungicida + aminoácido + inseticida & $78 \mathrm{a}$ & $71 \mathrm{a}$ & $58 \mathrm{~b}$ & $41 \mathrm{~b}$ & 62 \\
\hline Média & 72 & 66 & 58 & 43 & 60 \\
\hline C.V. & & & & & \\
\hline
\end{tabular}

*Tratamentos seguidos pela mesma letra pertencem ao mesmo grupo pelo teste de Scott-Knott, a 5\% de significância.

A avaliação do efeito das épocas de armazenamento revela redução na primeira contagem da germinação das sementes com o decorrer do tempo, sendo a função quadrática a que melhor se relacionou com os resultados (Figura 3 B). A redução do número de plântulas normais, na primeira contagem, possivelmente tenha as mesmas causas que levaram à redução da germinação (Figuras 1 e 2). Também foi observada uma redução mais acentuada na primeira contagem no período compreendido entre 120 e 180 dias após o tratamento.

O peso da massa seca das plântulas objetiva determinar com certa precisão a taxa de transferência de reservas para o embrião. Desta forma, sementes que originam plântulas normais com maior peso médio de massa seca, são consideradas mais vigorosas (Nakagawa, 1999). Na Figura 4A verifica-se redução mais acentuada no peso da massa seca das plântulas até os 120 dias após o tratamento das sementes, peso este que tende a uma estabilização a partir deste ponto. Esta redução foi de aproximadamente $26 \%$, demonstrando a perda da capacidade de translocação das reservas para o embrião. Para esta variável não foi constatado diferença entre tratamentos (Tabela 3).

Detectou-se redução linear na porcentagem de germinação das sementes comodecorrer doarmazenamento pelo teste de germinação à baixa temperatura (Figura 4B). Este comportamento pode estar relacionado com o maior rigor do teste de germinação à baixa temperatura, uma vez que as sementes são expostas a temperatura subótima. Além dos valores absolutos serem menores que os da primeira contagem, a redução do número de plântulas normais aumentou com o passar do tempo, variação esta de $50 \%$ entre a primeira e a última avaliação. De acordo com Dias e Mantovani (1999) sementes menos vigorosas apresentarão pior desempenho germinativo em condições de temperatura subótima com reflexos na velocidade de emergência. Quanto à massa seca das plântulas, não foi detectado diferenças entre os tratamentos (Tabela 3 ). 
Para as variáveis massa seca de plântula e germinação a baixa temperatura (Tabela 3) não houve diferenças entre os tratamentos e a testemunha. De forma geral, as análises laboratoriais demonstraram que a aplicação do aminoácido isolado melhora o desempenho das sementes, porém quando combinado com os outros produtos esta resposta não é obtida. Isto demonstra que há necessidade de novos estudos para melhor avaliar a combinação do aminoácido com outros fungicidas, inseticidas e polímeros.

TABELA 3. Peso da massa seca das plântulas de soja aos 5 dias (g) e germinação a baixa temperatura (\%), do cultivar CD 219, sem tratamento (testemunha) e tratadas e/ou recobertas com polímeros.

\begin{tabular}{|c|c|c|}
\hline Tratamentos & Massa seca da plântula (g) & Germinação a baixa temperatura $(\%)$ \\
\hline Testemunha & $0,298 \mathrm{a}$ & $35 \mathrm{a}$ \\
\hline Fungicida & $0,293 \mathrm{a}$ & $27 \mathrm{a}$ \\
\hline Aminoácido & $0,296 \mathrm{a}$ & $39 \mathrm{a}$ \\
\hline Polímero & $0,290 \mathrm{a}$ & $34 \mathrm{a}$ \\
\hline Fungicida + aminoácido & $0,289 \mathrm{a}$ & $28 \mathrm{a}$ \\
\hline Fungicida + inseticida & $0,299 \mathrm{a}$ & $31 \mathrm{a}$ \\
\hline Fungicida + polímero & $0,298 \mathrm{a}$ & $42 \mathrm{a}$ \\
\hline Fungicida + inseticida + polímero & $0,294 \mathrm{a}$ & $32 \mathrm{a}$ \\
\hline Fungicida + aminoácido + inseticida & $0,278 \mathrm{a}$ & $34 \mathrm{a}$ \\
\hline Média & 0,293 & 33 \\
\hline C.V. & 6,43 & 30,6 \\
\hline
\end{tabular}

*Tratamentos seguidos pela mesma letra pertencem ao mesmo grupo pelo teste de Scott-Knott, a 5\% de significância.
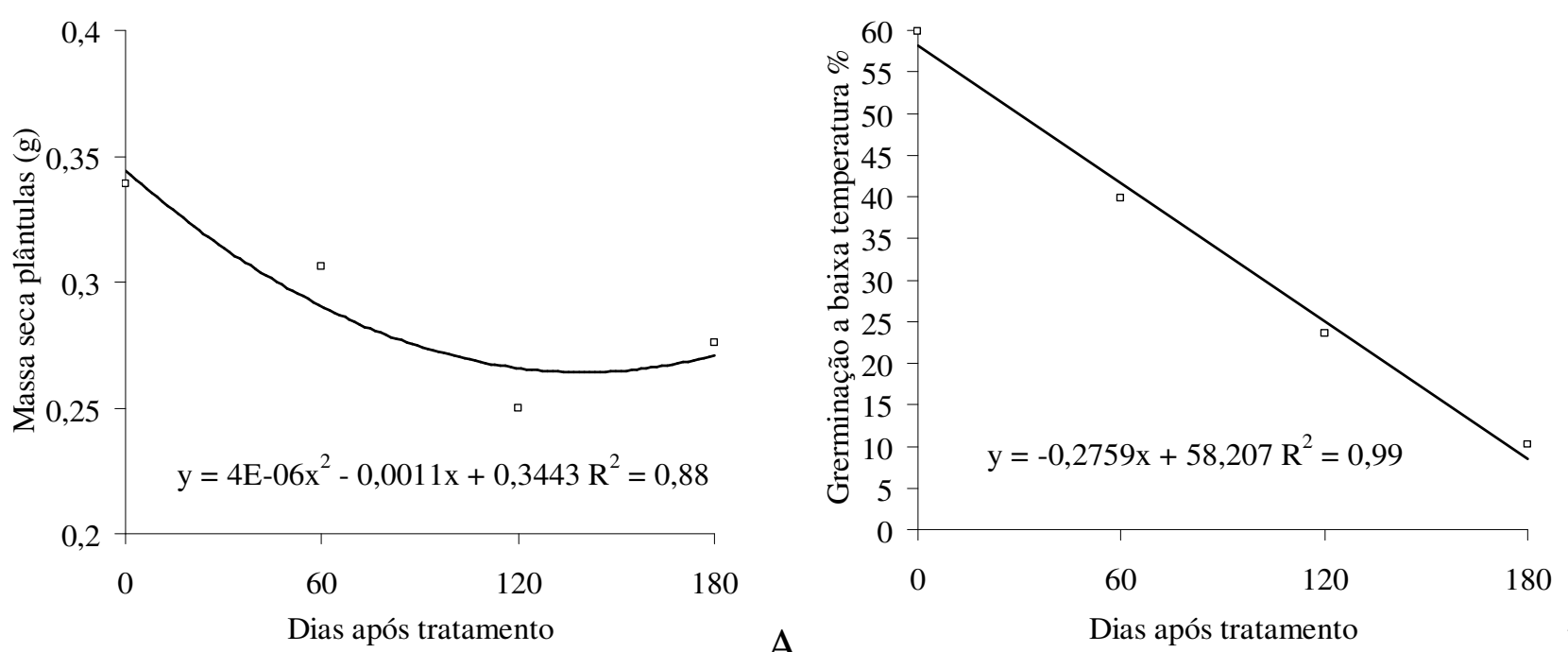

A

Dias após tratamento

B

FIGURA 4. Média de massa seca de plântulas de soja aos 5 dias (g) (A) e da germinação a baixa temperatura (\%) (B), do cultivar CD 219, armazenadas por 180 dias.

Ressalta-se a importância da detecção dos fungos fitopatogênicos da cultura, ainda nas sementes, e antes da semeadura, pois estes são capazes de causar doenças como a queima da haste e da vagem, mancha púrpura, além de antracnoses e fusarioses, que são doenças causadas por Phomopsis sp., Cercospora kikuchii, Colletotrichum 
spp. e Fusarium spp., (Henning, 2004). Observando os resultados da sanidade de sementes (Tabela 4) constatase uma redução dos fungos fitopatogênicos Rhizoctonia sp. (logo após o tratamento); Fusarium spp. (aos 180 dias após o tratamento); Colletotrichum sp. (aos 60 e 180 dias após o tratamento); Phomopsis sp. (aos 60 dias após o tratamento) e Alternaria spp. (aos 60 e 180 dias após o tratamento), quando da utilização de fungicida a única exceção é a Cercospora sp., o que demonstra a eficiência e os benefícios do tratamento de sementes com fungicidas.

TABELA 4. Incidência (\%) de fungos causadores de doença (Rhizoctonia sp.; Fusarium spp.; Colletotrichum sp.; Phomopsis sp.; Alternaria spp.; Cercospora sp.) em de sementes de soja da cultivar CD 219, sem tratamento (testemunha) e tratadas e/ou recobertas com polímeros e, armazenadas durante 180 dias.

\begin{tabular}{|c|c|c|c|c|c|c|c|c|c|c|}
\hline & 0 & 60 & 120 & 180 & Média & 0 & 60 & 120 & 180 & Média \\
\hline & \multicolumn{5}{|c|}{ Rhizoctonia sp. (\%) } & \multicolumn{5}{|c|}{ Fusarium spp. (\%) } \\
\hline Testemunha & $2,1 \mathrm{a}$ & $1,4 \mathrm{a}$ & $0,4 a$ & $0,5 \mathrm{a}$ & 1,1 & $4,4 \mathrm{a}$ & $3,0 \mathrm{a}$ & $1,8 \mathrm{a}$ & $3,0 \mathrm{a}$ & 3,0 \\
\hline Fungicida & $1,5 \mathrm{~b}$ & $0,9 \mathrm{a}$ & $0,3 a$ & $0,1 \mathrm{a}$ & 0,7 & $2,8 \mathrm{a}$ & $1,8 \mathrm{a}$ & $0,9 \mathrm{a}$ & $0,4 \mathrm{~b}$ & 1,5 \\
\hline Aminoácido & $1,0 \mathrm{~b}$ & $1,2 \mathrm{a}$ & $0,0 \mathrm{a}$ & $0,1 \mathrm{a}$ & 0,6 & $1,8 \mathrm{a}$ & $1,3 \mathrm{a}$ & $0,9 \mathrm{a}$ & $2,1 \mathrm{a}$ & 1,5 \\
\hline Polímero & $2,4 \mathrm{a}$ & $0,8 \mathrm{a}$ & $0,3 a$ & $0,0 \mathrm{a}$ & 0,8 & $1,9 \mathrm{a}$ & $1,1 \mathrm{a}$ & $0,1 \mathrm{a}$ & $0,1 \mathrm{~b}$ & 0,8 \\
\hline Fungicida + Aminoácido & $1,5 b$ & $0,9 \mathrm{a}$ & $0,0 \mathrm{a}$ & $0,1 \mathrm{a}$ & 0,6 & $4,0 \mathrm{a}$ & $1,4 \mathrm{a}$ & $0,4 a$ & $0,6 \mathrm{~b}$ & 1,6 \\
\hline Fungicida + Inseticida & $3,0 \mathrm{a}$ & $1,4 \mathrm{a}$ & $0,1 \mathrm{a}$ & $0,5 \mathrm{a}$ & 1,3 & $3,5 \mathrm{a}$ & $1,4 \mathrm{a}$ & $0,6 \mathrm{a}$ & $0,8 \mathrm{~b}$ & 1,6 \\
\hline Fungicida + Polímero & $1,5 b$ & $1,8 \mathrm{a}$ & $0,5 \mathrm{a}$ & $0,4 \mathrm{a}$ & 1,0 & $2,3 a$ & $2,3 \mathrm{a}$ & $1,0 \mathrm{a}$ & $1,0 \mathrm{~b}$ & 1,6 \\
\hline Fungicida + Inseticida + Polímero & $1,3 b$ & $1,0 \mathrm{a}$ & $0,4 \mathrm{a}$ & $0,3 \mathrm{a}$ & 0,7 & $3,0 \mathrm{a}$ & $1,3 \mathrm{a}$ & $0,4 \mathrm{a}$ & $0,6 \mathrm{~b}$ & 1,3 \\
\hline Fungicida + Aminoácido + Inseticida & $1,4 \mathrm{~b}$ & $0,5 \mathrm{a}$ & $0,3 \mathrm{a}$ & $0,0 \mathrm{a}$ & 0,5 & $2,5 \mathrm{a}$ & $1,9 \mathrm{a}$ & $0,5 \mathrm{a}$ & $0,3 \mathrm{~b}$ & 1,3 \\
\hline Média & 1,7 & 1,1 & 0,7 & 0,2 & & 2,8 & 1,7 & 0,7 & 1 & \\
\hline \multirow[t]{2}{*}{ C.V. } & \multicolumn{5}{|c|}{29,11} & \multicolumn{5}{|c|}{30,80} \\
\hline & \multicolumn{5}{|c|}{ Colletotrichum sp.(\%) } & \multicolumn{5}{|c|}{ Phomopsis sp. (\%) } \\
\hline Testemunha & $0,1 \mathrm{a}$ & $0,8 \mathrm{a}$ & $0,1 \mathrm{a}$ & $0,5 \mathrm{a}$ & 0,4 & $0,3 a$ & $0,5 \mathrm{a}$ & $0,0 \mathrm{a}$ & $0,0 \mathrm{a}$ & 0,2 \\
\hline Fungicida & $0,0 \mathrm{a}$ & $0,1 \mathrm{~b}$ & $0,0 \mathrm{a}$ & $0,0 \mathrm{~b}$ & 0,0 & $0,1 \mathrm{a}$ & $0,1 b$ & $0,0 \mathrm{a}$ & $0,0 \mathrm{a}$ & 0,1 \\
\hline Aminoácido & $0,1 \mathrm{a}$ & $0,1 b$ & $0,0 \mathrm{a}$ & $0,0 \mathrm{~b}$ & 0,1 & $0,0 \mathrm{a}$ & $0,0 \mathrm{~b}$ & $0,1 \mathrm{a}$ & $0,0 \mathrm{a}$ & 0,0 \\
\hline Polímero & $0,3 \mathrm{a}$ & $0,3 b$ & $0,0 \mathrm{a}$ & $0,0 \mathrm{~b}$ & 0,1 & $0,3 \mathrm{a}$ & $0,3 \mathrm{a}$ & $0,0 \mathrm{a}$ & $0,0 \mathrm{a}$ & 0,1 \\
\hline Fungicida + Aminoácido & $0,0 \mathrm{a}$ & $0,0 \mathrm{~b}$ & $0,0 \mathrm{a}$ & $0,0 \mathrm{~b}$ & 0,0 & $0,0 \mathrm{a}$ & $0,3 \mathrm{a}$ & $0,0 \mathrm{a}$ & $0,0 \mathrm{a}$ & 0,1 \\
\hline Fungicida + Inseticida & $0,1 \mathrm{a}$ & $0,1 b$ & $0,0 \mathrm{a}$ & $0,1 b$ & 0,1 & $0,3 a$ & $0,0 \mathrm{~b}$ & $0,0 \mathrm{a}$ & $0,0 \mathrm{a}$ & 0,1 \\
\hline Fungicida + Polímero & $0,0 \mathrm{a}$ & $0,0 \mathrm{~b}$ & $0,0 \mathrm{a}$ & $0,0 \mathrm{~b}$ & 0,0 & $0,0 \mathrm{a}$ & $0,1 b$ & $0,0 \mathrm{a}$ & $0,0 \mathrm{a}$ & 0,0 \\
\hline Fungicida + Inseticida + Polímero & $0,0 \mathrm{a}$ & $0,1 b$ & $0,0 \mathrm{a}$ & $0,1 b$ & 0,1 & $0,0 \mathrm{a}$ & $0,0 \mathrm{~b}$ & $0,0 \mathrm{a}$ & $0,0 \mathrm{a}$ & 0,0 \\
\hline Fungicida + Aminoácido + Inseticida & $0,0 \mathrm{a}$ & $0,0 \mathrm{~b}$ & $0,0 \mathrm{a}$ & $0,1 \mathrm{~b}$ & 0,0 & $0,3 \mathrm{a}$ & $0,0 \mathrm{~b}$ & $0,0 \mathrm{a}$ & $0,0 \mathrm{a}$ & 0,1 \\
\hline Média & 0,1 & 0,2 & 0,0 & 0,1 & & 0,1 & 0,1 & 0,0 & 0,0 & \\
\hline \multirow[t]{2}{*}{ C.V. } & \multicolumn{5}{|c|}{17,18} & \multicolumn{5}{|c|}{14,93} \\
\hline & \multicolumn{5}{|c|}{ Alternaria spp. (\%) } & \multicolumn{5}{|c|}{ Cercospora sp. (\%) } \\
\hline Testemunha & $0,0 \mathrm{a}$ & $0,5 \mathrm{a}$ & $0,1 \mathrm{a}$ & $0,5 \mathrm{a}$ & 0,3 & $0,4 \mathrm{a}$ & $1,6 \mathrm{a}$ & $0,5 \mathrm{a}$ & $0,3 \mathrm{a}$ & 0,7 \\
\hline Fungicida & $0,4 \mathrm{a}$ & $0,1 \mathrm{~b}$ & $0,0 \mathrm{a}$ & $0,0 \mathrm{~b}$ & 0,1 & $0,5 \mathrm{a}$ & $2,4 a$ & $0,3 \mathrm{a}$ & $0,3 \mathrm{a}$ & 0,9 \\
\hline Aminoácido & $0,0 \mathrm{a}$ & $0,0 \mathrm{~b}$ & $0,0 \mathrm{a}$ & $0,0 \mathrm{~b}$ & 0,0 & $0,9 \mathrm{a}$ & $0,5 b$ & $0,3 \mathrm{a}$ & $0,4 \mathrm{a}$ & 0,5 \\
\hline Polímero & $0,0 \mathrm{a}$ & $0,0 \mathrm{~b}$ & $0,0 \mathrm{a}$ & $0,1 b$ & 0,0 & $0,5 \mathrm{a}$ & $1,3 \mathrm{a}$ & $0,5 \mathrm{a}$ & $0,0 \mathrm{a}$ & 0,6 \\
\hline Fungicida + Aminoácido & $0,3 \mathrm{a}$ & $0,0 \mathrm{~b}$ & $0,0 \mathrm{a}$ & $0,0 \mathrm{~b}$ & 0,1 & $1,0 \mathrm{a}$ & $1,4 \mathrm{a}$ & $0,0 \mathrm{a}$ & $0,3 \mathrm{a}$ & 0,7 \\
\hline Fungicida + Inseticida & $0,0 \mathrm{a}$ & $0,0 \mathrm{~b}$ & $0,1 \mathrm{a}$ & $0,0 \mathrm{~b}$ & 0,0 & $0,1 \mathrm{a}$ & $1,3 \mathrm{a}$ & $0,0 \mathrm{a}$ & $0,1 \mathrm{a}$ & 0,4 \\
\hline Fungicida + Polímero & $0,1 \mathrm{a}$ & $0,0 \mathrm{~b}$ & $0,0 \mathrm{a}$ & $0,0 \mathrm{~b}$ & 0,0 & $0,5 \mathrm{a}$ & $0,9 b$ & $0,3 \mathrm{a}$ & $0,0 \mathrm{a}$ & 0,4 \\
\hline Fungicida + Inseticida + Polímero & $0,1 \mathrm{a}$ & $0,1 b$ & $0,0 \mathrm{a}$ & $0,1 b$ & 0,1 & $0,0 \mathrm{a}$ & $0,5 b$ & $0,3 \mathrm{a}$ & $0,3 \mathrm{a}$ & 0,3 \\
\hline Fungicida + Aminoácido + Inseticida & $0,0 \mathrm{a}$ & $0,1 b$ & $0,0 \mathrm{a}$ & $0,3 \mathrm{a}$ & 0,1 & $0,3 \mathrm{a}$ & $0,9 \mathrm{~b}$ & $0,0 \mathrm{a}$ & $0,0 \mathrm{a}$ & 0,3 \\
\hline Média & 0,1 & 0,1 & 0,0 & 0,1 & & 0,4 & 1,1 & 0,2 & 0,2 & \\
\hline C.V. & \multicolumn{5}{|c|}{16,38} & \multicolumn{5}{|c|}{30,94} \\
\hline
\end{tabular}

*Tratamentos seguidos pela mesma letra pertencem ao mesmo grupo pelo teste de Scott-Knott, a 5\% de significância. 
Menores valores de incidência de fungos foram observados com uso de aminoácido em comparação com a testemunha Rhizoctonia sp. (logo após o tratamento); Colletotrichum sp. (aos 60 e 180 dias após o tratamento); Phomopsis sp. (aos 60 dias após o tratamento) e Alternaria spp. (aos 60 e 180 dias após o tratamento), Cercospora sp. (aos 60 dias após o tratamento). Estes resultados concordam com os observados por Priyachem (2008), que relata a redução de fungos como Fusarium oxysporum, $F$. ciceri, Macrophomina phaseolina e Rhizoctonia solani, com uso de aminoácido na semente, o que possivelmente esteja relacionado com a composição dos aminoácidos no produto utilizado. A Rhizoctonia sp. foi o único fungo encontrado nas sementes de todos os tratamentos.

A utilização do polímero não afetou o desempenho do fungicida quando combinados, pois a utilização deste

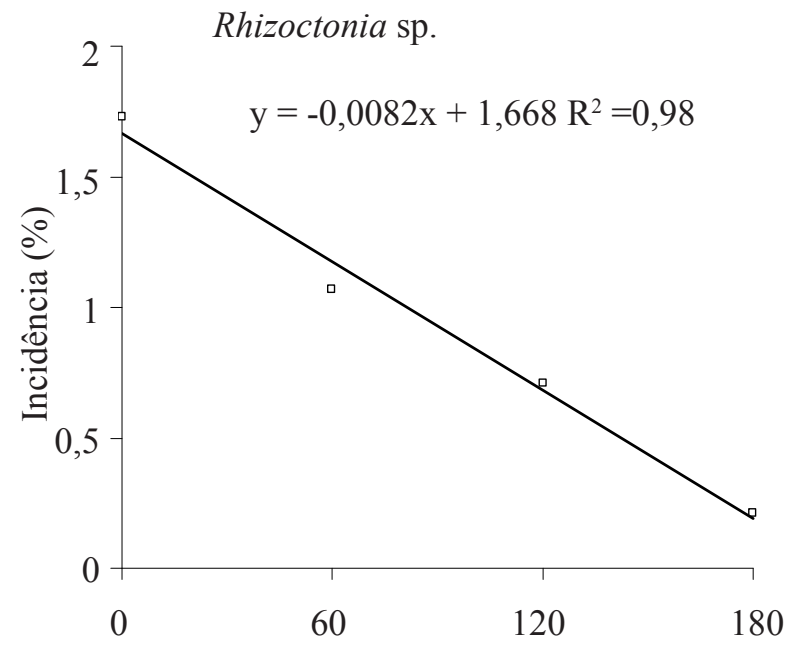

Dias após tratamento

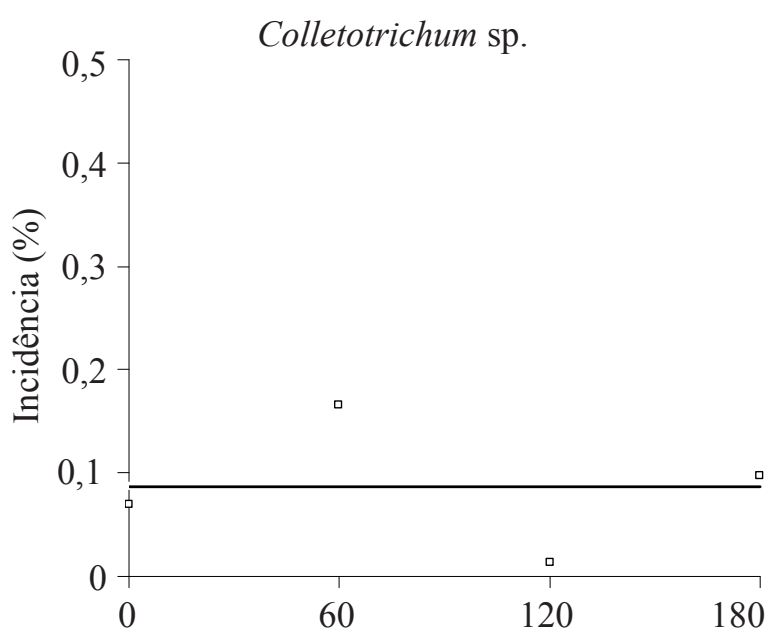

Dias após tratamento produto não alterou a presença de fungos nas sementes. Para o fungo Cercospora sp., aos 60 dia após o tratamento, o uso do polímero melhorou o efeito do fungicida através da combinação. Resultado este que indica que a utilização do produto é viável e não afeta o desempenho do fungicida sobre o controle de fungos.

O comportamento dos fungos no decorrer das avaliações foi diferenciado, sendo que não houve diferença na incidência dos fungos Colletotrichum sp. e Alternaria spp. no decorrer das avaliações (Figura 5C e 5E). Já para os fungo Rhizoctonia sp. e Phomopsis sp. houve redução linear da incidência (Figura $5 \mathrm{~A}$ e $5 \mathrm{D}$ ). Resultado semelhante foi obtido por Henning (2004) para Phomopsis sp. Já a incidência dos fungos Fusarium spp. e Cercospora sp. apresentaram resposta quadrática ao armazenamento (Figura 5B e 5F)

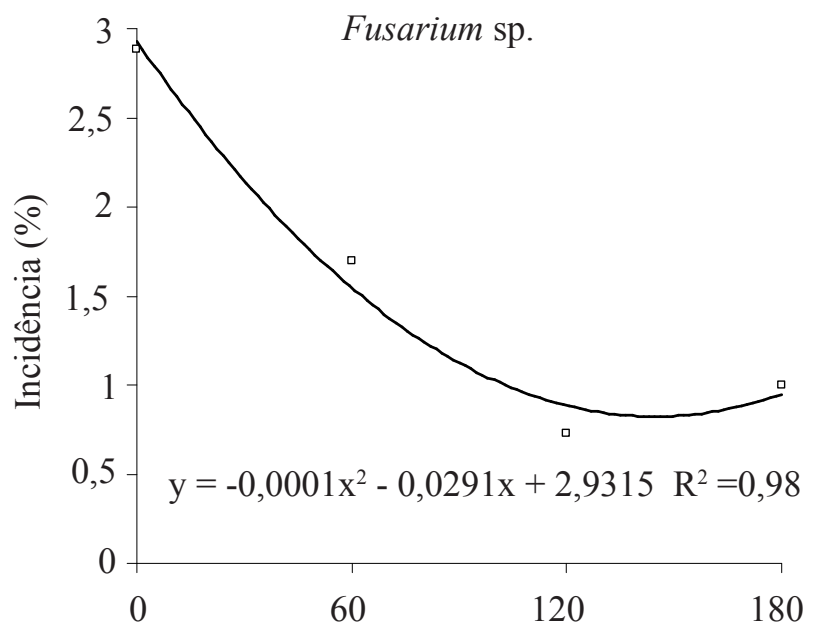

A

Dias após tratamento

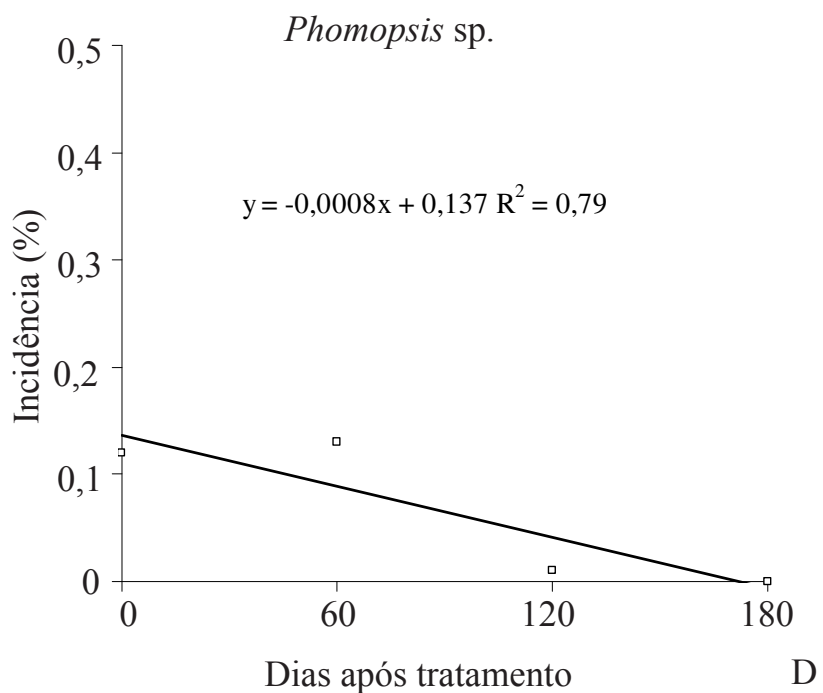



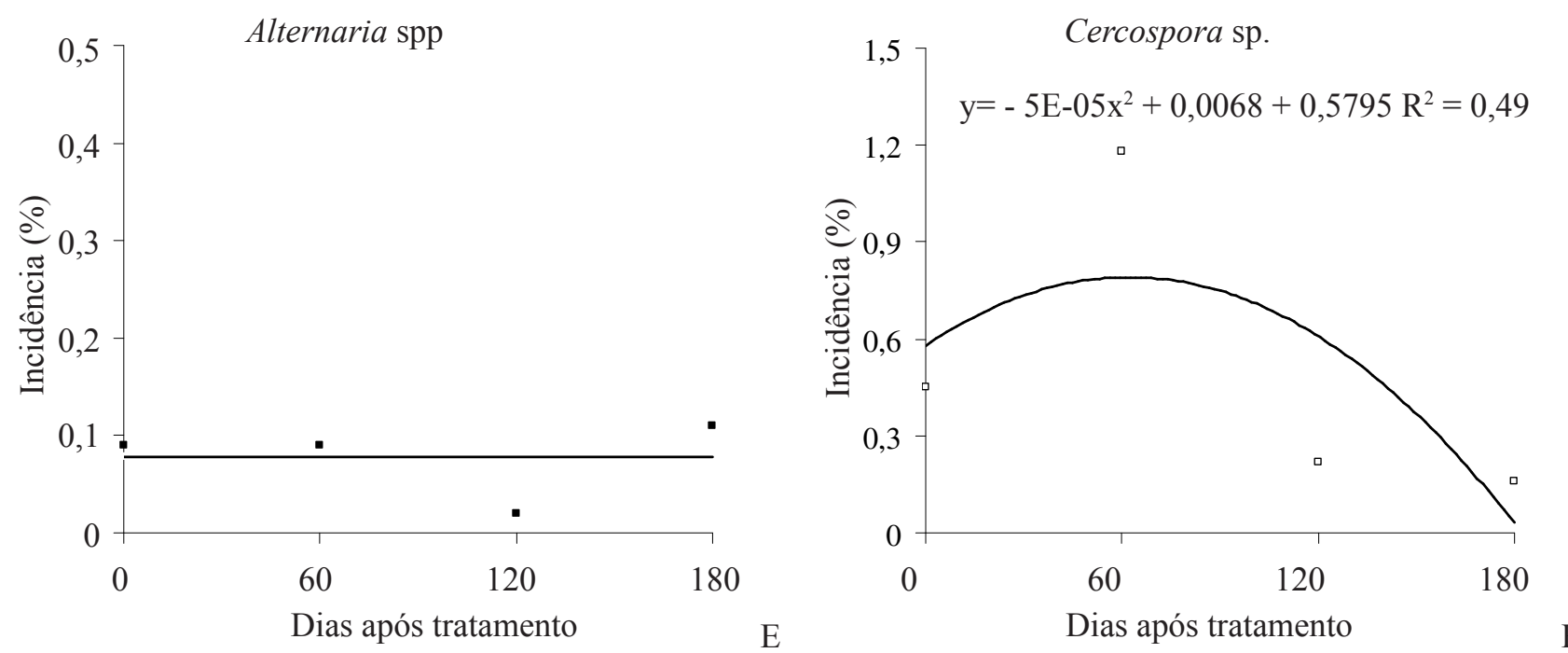

FIGURA 5. Incidência (\%) de fungos causadores de doença (Rhizoctonia sp. (A); Fusarium spp. (B); Colletotrichum sp. (C); Phomopsis sp. (D); Alternaria spp. (E); Cercospora sp. (F)) em de sementes de soja do cultivar CD 219, não tratada (testemunha) e tratadas e/ou recobertas e armazenadas em condições não controladas por 180 dias.

\section{CONCLUSÕES}

A aplicação do aminoácido isolado afeta positivamente a germinação, porém quando combinado com fungicida e polímero não melhora o desempenho das sementes de soja.

A germinação é afetada negativamente com o uso do fungicida, porém combinação de fungicida e polímero não apresenta este efeito.

A aplicação do fungicida reduziu a incidência dos fungos avaliados, com exceção da Cercospora sp..

A utilização de polímero não afeta o controle de fungos pelo fungicida, indicando que a combinação dos mesmos pode ser utilizada.

\section{REFERÊNCIAS}

BAUDET, L.; PESKE, S.T. A logística do tratamento de sementes. Seed News, v.10, n.1, p.20-23, 2006.

BAUDET, L; VILLELA, F.A. Armazenamento de Sementes. In.: PESKE, S.T.; LUCCA FILHO. O.A.; BARROS, A.C.S.A. (Ed.). Sementes: fundamentos científicos e Tecnológicos, 2.Ed. Pelotas, 2006, p.427-472.
BAYS, R.; BAUDET, L.; HENNING, A.A.; LUCCA FILHO, O. Recobrimento de sementes de soja com micronutrientes, fungicida e polímero. Revista Brasileira de Sementes, v.29, n.2, p.60-67, 2007. http://www.scielo. br/pdf/rbs/v29n2/v29n2a09.pdf.

BRASIL. Ministério da Agricultura e Reforma Agrária. Secretaria NacionaldeDefesa Agropecuária.Departamento Nacional de Produção Vegetal. Coordenação de Laboratório Vegetal. Regras para análise de sementes. Brasília, DF, 1992. 365p.

DIAS, D.C.F.S.; ALVARENGA, E.M. Teste de germinação a baixa temperatura. In.: KRZYZANOWSKI, F.C.; VIEIRA, R.D.; FRANÇA NETO, J.B, Vigor de sementes: conceitos e teste. Londrina: ABRATES, 1999. p.7-1-7-3.

ESTAÇÃO AGROCLIMATOLÓGICA DE PELOTAS. Boletim agroclimatológico dos meses de outubro de 2007 a abril de 2008. EMBRAPA/CPACT, Recursos Naturais UFPEL, FAEM/Fitotecnia, INMET/8. DISME. http://www.cpact.embrapa.br/agromet.

FERREIRA, D.F. Software Sisvar: versão4.6, Universidade Federal de Lavras, Lavras. 2003.

FLOSS, E.L.; FLOSS, L.G. Fertilizantes organo 
minerais de última geração: funções fisiológicas e uso na agricultura. Revista Plantio Direto, n.100, 2007. http:// www.plantiodireto.com.br/?body $=$ cont int\&id $=811$.

GOULART, A.C.P. Eficiência de diferentes fungicidas no controle de patógenos em sementes de soja e seus efeitos na emergência e no rendimento de grãos da cultura. Informativo Abrates, v.10, n.1/2/3, p.17-24, 2000.

HENNING, A.A. Patologia e tratamento de sementes: noções gerais. Londrina: Embrapa Soja, 2004, 51p. (Embrapa. Soja. Documentos, 235).http://www.cnpso. embrapa.br/download/alerta/documento235.pdf, Acesso em: 05 fev. 2008.

IBGE - Confronto das Safras de 2009 e das Estimativas para 2010 - Brasil. http://www.ibge.gov.br/home/ estatistica/indicadores/agropecuaria/lspa/ defaulttab. shtm. Acesso em 16 fev. 2010.

KARAM, D.; MAGALHÃES, P.C.; PADILHA, L. Efeito da adição de polímeros na viabilidade, no vigor e na longevidade de sementes de milho. Sete Lagoas: Embrapa Milho e Sorgo, 2007. 5p.(Embrapa Milho e Sorgo. Circular Técnica, 94). http://www.cnpms.embrapa. br/publicacoes/publica/2007/circular/Circ_94.pdf,Acesso em: 05 fev. 2009.

DIAS, D.C.F.S.; ALVARENGA, E.M. Teste de germinação a baixa temperatura. IN: KRZYZANOWSKI, F.C.; VIEIRA, R.D.; FRANÇA NETO, J.B. (Ed.). Vigor de sementes: conceitos e testes. Londrina: ABRATES, 1999. Cap. 7. P. 7.1-7.3.

KUNKUR, V.; HUNJE, R.; PATIL, N.K.B.; VYAKARNHAL, B.S. Effect of Seed Coating with Polymer, Fungicide and Insecticide on Seed Quality in Cotton During Storage. Karnataka Journal of Agricultural Sciences, v.20, n.1, p.137-139, 2007. http://203.129.218.157/ ojs/index.php /kjas/article / viewFile/42/42.

LUCCA FILHO, O.A. Patologia de Sementes. In.: PESKE, S.T.; LUCCA FILHO, O.A.; BARROS, A.C.S.A. (Ed.). Sementes: fundamentos científicos e Tecnológicos, 2.Ed., Pelotas, p.259-329, 2006.

LUZ, W.C.; PEREIRA, LR. Tratamento de sementes com fungicida relacionado com o controle de patógenos e rendimento de milho. Ciência Rural, v.28, n.4, p.537541, 1998. http://www.scielo.br/pdf/cr/v28n4/a01v28n4. pdf.

NEERGAARD, P. Incubation tests. In: Seed Pathology. London: Macmillan Press, 1977. 839p.

NAKAGAWA, J. Teste de vigor baseados no desempenho das plântulas. In.: KRZYZANOWSKI, F. C.; VIEIRA, R.D.; FRANÇA NETO, J.B. Vigor de sementes: conceitos e teste. Londrina: ABRATES, p.2-1-2-21, 1999.

PEREIRA, C.E.; OLIVEIRA, J.A.; EVANGELISTA, J.R.E. Qualidade fisiológica de sementes de milho tratadas associadas a polímeros durante o armazenamento. Ciência e Agrotecnologia, v.29, n.6, p.1201-1208, 2005. http:// www.scielo.br/pdf/cagro/v29n6/v29n6a14.pdf.

PRIYACHEM. Ankur. http://www.priyachem.com/ ankur.htm. Acesso em: 14 abr. 2008.

ZIMMER, P. D. Fundamentos da qualidade de semente. In.: PESKE, S.T.; LUCCA FILHO, O.A.; BARROS, A.C.S.A. (Ed.). Sementes: fundamentos científicos e Tecnológicos, 2.Ed. Pelotas, 2006, p.99-158. 